\title{
'Are these adult doctors gonna know me?' Experiences of transition for young people with a liver transplant
}

DOI:

10.1111/petr.12777

\section{Document Version}

Accepted author manuscript

Link to publication record in Manchester Research Explorer

\section{Citation for published version (APA):}

Wright, J., Elwell, L., Mcdonagh, J., Kelly, D. A., \& Wray, J. (2016). 'Are these adult doctors gonna know me?' Experiences of transition for young people with a liver transplant. Pediatric transplantation, 20(7), 912-920. https://doi.org/10.1111/petr.12777

\section{Published in:}

Pediatric transplantation

\section{Citing this paper}

Please note that where the full-text provided on Manchester Research Explorer is the Author Accepted Manuscript or Proof version this may differ from the final Published version. If citing, it is advised that you check and use the publisher's definitive version.

\section{General rights}

Copyright and moral rights for the publications made accessible in the Research Explorer are retained by the authors and/or other copyright owners and it is a condition of accessing publications that users recognise and abide by the legal requirements associated with these rights.

\section{Takedown policy}

If you believe that this document breaches copyright please refer to the University of Manchester's Takedown Procedures [http://man.ac.uk/04Y6Bo] or contact uml.scholarlycommunications@manchester.ac.uk providing relevant details, so we can investigate your claim.

\section{OPEN ACCESS}


Title: 'Are these adult doctors gonna know me?' Experiences of transition for young people with a liver transplant.

$$
\text { Wright } \mathrm{J}^{1} \text {, Elwell } \mathrm{L}^{1,2}, \mathrm{McDonagh}^{\mathrm{J}} \mathrm{E}^{3} \text {, Kelly } \mathrm{DA}^{1} \text {, Wray } \mathrm{J}^{4}
$$

1Liver Unit, Birmingham Children's Hospital NHS Foundation Trust, United Kingdom

2University of Birmingham, United Kingdom

${ }^{3}$ Centre for Musculoskeletal Research, University of Manchester, United Kingdom

${ }^{4}$ Critical Care and Cardiorespiratory Division, Great Ormond Street Hospital for Children NHS Foundation Trust, United Kingdom

Corresponding author: Dr Jo Wray

Contact e-mail: jo.wray@gosh.nhs.uk

Contact telephone: +442078297822

Contact address: Great Ormond Street Hospital for Children NHS Foundation Trust Great Ormond Street, London WC1N 3JH

Key words: young people, liver transplant, transition, qualitative

Running title: Experiences of transition 


\begin{abstract}
Background

Excellent survival rates in paediatric liver transplantation have resulted in increasing numbers of young people transferring from paediatric to adult care. Understanding the mechanisms of successful transition is imperative for ensuring good long-term outcomes and developing services for young people.

Methods
\end{abstract}

Semi-structured interviews were conducted with seventeen young people (10 female; age range: 15.2-25.1 years). Eight were within one year of transferring to adult services; nine had transferred. Interviews were analysed using Interpretative Phenomenological Analysis.

Results

Analysis revealed two major themes in both pre and post-transfer groups: "Relationships with healthcare professionals" and "Continuity of care". Young people experienced difficulty ending relationships with paediatric clinicians and forming new relationships with adult clinicians. They expressed frustrations over a perceived lack of continuity of care after transfer and a fear of the unknown nature of adult services. The importance of a holistic approach to care was emphasised.

Conclusions

Interventions are needed to support young people in transition, particularly in ending relationships in paediatric care and forming new relationships in adult care. Young people need help to develop strategies to cope with the different approaches in adult services. 
Interventions to provide clinicians with skills to communicate and engage with young people are imperative. 


\section{Introduction}

More than $90 \%$ of young people with a special health care need survive into adulthood (1) resulting in increasing emphasis on the importance of transitional care. Transition emphasises a multi-faceted process, whereby the medical, educational, vocational and psychosocial needs of the patient are incorporated into a purposeful, planned programme.(2) The goal of transition is to provide young people with an individually tailored, developmentally appropriate and efficiently co-ordinated programme.

Transition is a potentially risky time due to the complex medical and psychosocial issues faced by young people. A number of national and international policy documents advocate the importance of addressing and incorporating wider needs into the transition process for young people, in addition to providing optimal healthcare(3-5). With the requirement for transition programmes established, there is now emphasis on how these programmes are deemed to be effective. The importance of co-ordinated and evidence based programmes has been highlighted (6-8) with suggestions for improving processes including joint transition clinics to promote continuity of care (9) and beginning preparation at an early stage to optimise the opportunity to develop independence. $(6,10)$ Furthermore, dedicated clinics and knowledge and skills training for young people have been identified as integral components to successful transition programmes with potential of transition co-ordinators and enhanced follow-up being proposed by the same authors.(8)

There are, however, many issues that hinder successful transition which need to be understood. Common barriers to transition include lack of preparation, the potential negative effect of losing existing relationships with paediatric clinicians, negative impressions of adult 
services by patients and parents (11) and little consideration of individual transition readiness and developmental status. $(12,13)$ Further barriers include a lack of communication between paediatric and adult care providers (14) and the potential difficulty caused by the differences in approaches adopted by paediatric and adult services.(15)

Although the success of paediatric liver transplantation (LTX) (16) has supported the development of transitional services for young people, research has focused primarily on medical outcomes rather than patient experience. In a recent survey of attitudes to transition, young people with a LTx reported moderate concern about transition, particularly about leaving paediatric providers, and demonstrated poor knowledge about the process.(17) Furthermore, adherence to medication regimens significantly decreases after transfer (18) and there is an increased incidence of graft loss in this age range.$(19,20)$ It is therefore crucial that transition services are developed which address potential barriers and improve long-term health outcomes. Research suggests that an understanding of patient needs and perspectives is vital to be able to do this, $(21,22)$ and qualitative rather than quantitative methods have been identified as particularly suitable for eliciting patient experiences. However, there is little qualitative research involving young people with a solid organ transplant, and in particular little which explores the views and experiences of young people with a LTX of transition. Only one qualitative study involving LTX recipients $(n=3)$ as part of a larger group of solid organ recipients was found (23) and whilst a number of broad themes related to transition were identified in the thematic analysis, the authors acknowledged the limitation of not including any patients who had transferred to adult services. Furthermore, the study design and sample size precluded the authors from looking at the perceptions of specific groups of organ recipients. Barriers and facilitators to successful transition are 
therefore difficult to identify for liver tx recipients from existing evidence and are speculative at best.

The current study aimed to explore the views and perceptions of young people with a LTX who were about to, or who had already, transferred to adult care to understand their experience of transition and to elicit what they believe constitutes "good" transition.

\section{Materials and methods}

Sampling and participants

Patients were eligible for inclusion if they had undergone a LTX and were either in the process of transition, or had been transferred to adult care within the last five years. Seventeen young people with a mean age of $20 \pm 3.1$ years (15.2-25.1 years) were recruited for interview representing a largely homogenous, purposive sample. Participants had undergone paediatric liver transplantation a mean of $10.3 \pm 6.0$ years (1.2-20.3 years) prior to interviews taking place, were in mid - late adolescence or early adulthood, had stable medical conditions and were being followed up as outpatients in a specialist liver unit in the UK. Further demographic information can be found in Table 1.

\section{Design and setting}

A qualitative semi-structured interview design was used to explore and obtain in-depth insight into specific experiences with regard to transition and paediatric LTx. (24) Interviews were conducted by the first author when young people attended a LTx clinic for routine clinic appointments at one of four acute settings in the United Kingdom. All four liver units have a national liver transplantation programme, which involves education and preparation prior to 
transfer and being seen by an adult clinician with a special interest in young people once in the adult centre. Whether or not patients were seen in a joint paediatric/adult clinic varied, even within the same programme. In both paediatric centres young people were encouraged to see the clinician without their parents for at least part of their appointment although the degree to which this happened depended on the individual young person. In general, patients were only transitioned from paediatric to adult services when they were clinically stable and had completed secondary education. Interviews took place in a private consultation room independent of caregivers and one interview took place via the telephone.

\section{Procedure}

Participants were invited for interview by a member of the clinical team and were telephoned by the researcher to establish a suitable time and place for the interview to take place. All participants were provided with an information sheet and gave informed consent prior to taking part.

Interviews began with a brief introduction to the purpose of the study and participants were given the opportunity to ask questions if they wished. Questions to participants focused on transition, including their own experiences of transition, the transfer event itself (if applicable) and what comprises successful (or unsuccessful) transition from their perspective. During this time the interviewer adopted a minimalist passive approach to encourage a narrative response. An interview schedule was used to guide question topics. Due to the exploratory nature of the study, interviews were flexible and guided by the interviewee with the interview schedule highlighting areas of interest rather than being used prescriptively. Interviews lasted approximately 45 minutes. 
Ethical approval was obtained from an NHS Research Ethics Committee.

\section{Data analysis}

Interviews were analysed using Interpretative Phenomenological Analysis (IPA),(25) a qualitative approach which combines idiographic and phenomenological components and which has been widely used in studies of chronic illness experience, including experiences of transition (26). IPA focuses on the lived experience of the participant and endeavours to make sense of the meanings of experiences. Analysis followed the four-step process outlined by Smith and Osborn.(27) After interviews were transcribed verbatim, each transcript was read and re-read by the first and second authors to facilitate familiarisation with interview content. Notes were made by the researchers of anything of significance. Transcripts were then coded individually using initial notes for guidance. Themes in the data were identified and those that were meaningfully associated were collated resulting in a list of superordinate and subordinate themes with the whole process of emergent themes and checking back with the transcript developing cyclically. The authors met regularly to discuss themes, and a final consolidated list was produced. In order to maintain congruence with the IPA approach of homogeneity, transcripts from the pre-and post-transfer subgroups were analysed separately and the findings subsequently triangulated. Qualitative analysis software was used throughout to support the analytical process (NVivo version 9.2).

\section{Results}

Analysis of the interviews highlighted two themes: 'relationships with healthcare professionals' and 'continuity of care', both of which were discussed in the context of 
transfer. Although the interviews were framed in terms of the transition process, all of the young people focused on the actual event of transfer, either in terms of their anticipation of it or their experiences of it. Themes have been broken down into smaller sub-themes to provide a closer examination of the data.

\section{Relationships with healthcare professionals}

There was a consistent theme of the importance held by young people of their relationships with healthcare professionals. The nature and implications of these relationships varied depending on the context but all of the young people discussed them. The new and undeveloped relationships with clinicians in adult services were sometimes seen as contributing to a negative experience, which young people contrasted with their positive relationships with paediatric clinicians which had often been developed over many years.

"They don't know me"

The theme of not being known by the adult team was described by young people both before and after transplant. Those who had already transferred discussed feeling unknown by adult clinicians in contrast to their feelings about paediatric clinicians where they had been known to the service for a significant amount of time and therefore relationships were well established.

"It's nothing like the kids. I've just seen the doctor, I haven't got a clue who she is, she doesn't know me, she's never met me. She's sorting me out but it's not the same when you see the doctors that you know all the time." [Participant 28 -post-transfer] 
Feelings of being unknown went beyond the healthcare professional's knowledge of the patients' medical condition, medications and previous procedures as many young people commented that this information was readily available to clinicians during consultations via their patient notes. Despite clinicians having medical knowledge of their patients, for the young people this knowledge did not constitute "being known" in a holistic sense and it was the personal connection and relationship they felt was missing and provided a barrier to communication.

"The doctors I suppose, they don't really know you as well either so it'd be a bit harder I suppose to, like talk to them as confidently I guess. Because they won't know much about you other than they'll obviously know what they've got in the file." [Participant 18 - pre-transfer]

Young people discussed their anxiety about being unknown before they transferred to adult services and how important those existing bonds and relationships were to them. The following quote from a young person who had transferred reflects the anxieties they had while still in the paediatric clinic and the importance to them of being seen by someone who "really knows" them.

"Well are these adult doctors gonna know me? Y'know are they gonna know me? And I know they've got it in the notes...And I feel, y'know I found I'm saying to [paediatric doctor], you're the only one that knows me... and I want to stick to someone who knows me." [Participant 15 - post-transfer]

Young people discussed the importance of the clinicians taking an active role in rapport building. This was felt to be an important part of being known and impacted upon young people's attitudes towards adult services. 
"You have to form a relationship with me or - if I don't feel like you've took the time to form that relationship with me...I'll sit there and probably like, listen to you, but I'm not gonna take it in........ [Paediatric doctor] used to be cool and that, and just used to talk to me like normal and that like, asking me about normal things and stuff, what do I do, y'know, take time out and that. And I noticed them things." [Participant 11 post-transfer]

"It was sad to go"

Young people talked extensively about their relationships with paediatric clinicians. This relationship was described positively and, for many of them, had been a substantial and significant relationship in their lives for many years. Young people found the idea of "ending" this relationship painful and emotional:

"I have good memories. And I have good memories of the staff, I have good memories of the patients, I have good memories of the doctors, I have good memories of the surgeons, the transplant--I have good memories but I also have a lot of bad memories. But it was, it was sad to go. To explain it all, one way, [it] was sad to go I think. I felt, it was sad to go." [Participant 15 - post-transfer]

This young person had transferred to adult services but was reflecting upon his "good" memories of paediatrics, even in the face of medically challenging circumstances, such as transplantation and multiple surgical procedures. It took him a while to come to the conclusion that he felt sad about leaving paediatric services, indicating the complex range of emotions involved in this process. Feeling sad about moving to adult services might be a 
difficult emotion to accept in light of the potentially positive connotations i.e. being well enough to be transferred, which in itself is a triumph.

Substantial components of young people's positive relationships with paediatric services were comfort and understanding. This idea that patients receive feelings of emotional support and reassurance provides a context for why some young people can find this change a difficult time.

"I feel like comfortable with these people I'm with now. And I feel like if I had any problems or anything then they'd always listen to it. "[Participant 6 - pre-transfer] Related to feelings about leaving paediatric services, some young people described how they had coped with the transfer. One young person talked about how they drew on their experiences of coping with other stressful situations to help them face the challenges of moving to adult services.

"You can worry about it all you want but it's gonna happen at the end of the day so you might as well just get on with it. And I've had to do that with most things in my life, like I've been through a lot including my liver transplant so, it's sort of, made me have a very blasé look at everything. Like, oh well it's just gotta happen sort of thing, that's what I've gotta do." [Participant 10 - post-transfer]

\section{Continuity of care}

Continuity of care was highlighted by all participants, whether with reference to how they felt transfer might affect their continuity of care when it occurred or from participants who had 
already transferred and were reflecting on their experiences. This theme is separated into the following subthemes: "fear of the unknown" and "it's like meet and greet again."

"Fear of the unknown"

Young people discussed a fear of the unknown in relation to feelings about adult services prior to transfer. Participants were anxious about the impending transfer and anxiety was derived from a feeling of not knowing what adult services would be like.

"It's probably just because I'm used to it I suppose. And people are just friendlier and I know that they're friendly here and everything's very relaxed. I just don't know exactly what's going on at the adult one. Probably just fear of the unknown I suppose." [Participant 3 - pre-transfer]

Another young person reiterated uncertainty about life in adult services but in contrast to participant 3, participant 25 had already transferred to adult services and was reflecting on her experience of arriving at the hospital for her first appointment in adult care.

"At the children's I knew what was gonna be happening, it was a routine that I was doing, I knew what would be happening every day. Not like with this one. I didn't know what was gonna be going on." [Participant 25 - post-transfer]

Some young people gave examples of how this "fear of the unknown" might be avoided with hindsight of having gone through this process. This involved having the opportunity to meet adult clinicians prior to transfer to remove the unknown element of transition and to keep a link contact with someone in paediatrics during transition. 
"I met [transition nurse] while I was still at the children's and she explained who she was and $y^{\prime}$ know what she did and stuff. Then they were here when I had my first appointment, and [paediatric clinician] was here as well so it wasn't just, here's new people, talk to them now, $y^{\prime}$ know there was some, continuity of care."[Participant 16post-transfer]

Participants who had not yet transferred also identified the potential benefits of maintaining a link with paediatric services.

"In fact I had a meeting with [nurse] and they kind of told me, I think what was really nice actually was that they gave me their contact details so that if I ever had any issues with it [adult services] I could talk directly to them and I do feel like when I get there I'll be fine". [Participant 2 - pre-transfer]

The benefits of meeting adult clinicians were also discussed by participants pre-transfer in terms of facilitating some familiarity on arrival in the adult service.

"It'd be nice to meet, like, the doctors before I started coming then I'll know who it was and I'd already know who I was going to be talking to". [Participant 6 - pretransfer]

"It's like meet and greet again"

Young people who had transferred discussed their frustrations at seeing different clinicians at each outpatient appointment and the repetition which framed each appointment when asked for their medical history at the start of a consultation. They did not perceive this process to be a mechanism of assessing self-management or gaining an understanding of their knowledge 
of their own condition. Rather, they perceived this as confirmation that the clinician did not know them which seemed to then hinder the process of the consultation.

"If I'm coming in every week and every time it's a different person, it's like meet and greet again. What are your illnesses? How did it start off? Every time I go in there they make me start from scratch." [Participant 11 - post-transfer]

Participants did not see the benefit in repeating this information and as a result tended to disengage. In contrast, one young person talked about her positive experience of seeing a clinician she had previously met and how this continuity of care impacted upon their subsequent relationship.

"The past couple of times I've been, I've seen the same doctor each time and he remembers so he'll like flick through his notes and then it obviously refresh[es] his memory and it's a lot easier to talk to him then. They can coordinate with you a bit better whereas somebody that's never met you, there's hundreds of patients. It's a lot nicer for you because you don't really like talking to people you don't know." [Participant 28 - post-transfer]

At the end of the interview young people who had transferred were specifically asked what would have helped them during the transfer to the adult service and the main focus was on reducing uncertainty and increasing familiarity by meeting staff and visiting the adult centre, as mentioned above. One challenge that was identified was that young people who are only being seen annually "forget" that they are transferring and it can be more difficult for them to have sufficient opportunity to become familiar with adult services before they move. The potential value of meeting other patients was also mentioned. 
"I know it sounds a bit full on but y'know, like meeting some of the patients before I actually went to (adult centre) and then some of the nurses and things like that would've been good." [Participant 24-post-transfer]

Others emphasised the importance of parents being able to be present during their clinic visits despite being in adult services.

"Someone like Mum or Dad ...being with me and telling me what's going to happen, like, most of the time whenever we go in to see a doctor I don't talk much because I don't' understand, 'cause I find it difficult, it's complicated. So Mum and Dad, if they speak to the doctor......they usually tell me what, $y^{\prime}$ know what's happened, $y^{\prime}$ know, or if I want to know what's happening, I'll ask them, but most of the time, and it's not that I'm not interested, I am, but sometimes it's just, I don't y'know, listen that much because I find it very hard to take in." [Participant 25 - post-transfer]

This young person reported feeling "nervous" before talking to adult clinicians and not always understanding what was said to her, which she contrasted with communication in paediatric services where she felt explanations were better for her.

Similar anxieties about parents being able to be present in an adult clinic were also expressed by participants pre-transfer.

"I'm a bit worried about going to the adult clinic. I'm not that confident with myself and, like, I always trust that my mum and dad are there with me so they [adult clinic] are like differed that they [mum and dad] are not always going to be there with me". [Participant 3 - pre-transfer] 
Whilst the qualitative nature of this study precluded evaluation of the impact of demographic or medical factors such as gender or time since transplant on young people's transition experience, some of the participants who were older at the time of their transplant did suggest that the transfer to adult services was easier for them than for those who had been transplanted as young children. The young person in the following quote was transplanted shortly before transferring to the adult centre after a relatively short period of illness and so had not developed the same degree of rapport with the paediatric team as those transplanted at a younger age. She also identified that the team had treated her in a more adult way from the time of her transplant.

"I suppose it's just because, especially if you've had a long standing condition, like, if you've been at the children's hospital, then you get used to being treated a certain way. And then when you move to adult services, they're not paediatric doctors, and they're not paediatric nurses so they don't, act in the same way that you're used to. I mean, because I was sixteen when I was diagnosed, I was quite mature, anyway, $y^{\prime} k n o w$. They didn't talk to me like, they did, like the little kids because, that would've been.....patronising." [Participant 16 - post-transfer]

A number of young people found it hard to identify what they thought did or would make their transition better, but several "negotiated" a longer stay in children's services, despite being told that they would be transferring at their next appointment, which then helped them feel more in control of the transfer to adult services.

"I managed to swindle an extra two years there and then they said, y'know you definitely have to go this time so I was like, alright OK then........ keeping me an extra 
two years was like, really like wow they really think a lot of me, 'cause they didn't do that with anyone else." [Participant 10 - post-transfer]

Young people who had not yet transferred also found it difficult to articulate what preparation they had received for moving to adult services. They were unclear about whether they had received written information but did talk about 'chats' they had had with nurses in particular, and also about a 'day' when young people who were due to move to adult services got together. The following quote from a young person in response to being asked what they had been told about transitioning to adult services characterises responses of participants pre-transfer.

"They've just like said "you'll be fine", "it's just gonna be like normal and they'll talk to you" and I don't know, just like........ I don't know". [Participant 19- pre-transfer]

\section{Discussion}

The purpose of this study was to understand the experiences of transition from the perspective of young people with a LTx in the light of disappointing outcomes documented in the LTx literature following transfer to adult care(18-20). In contrast to most of the research on transition in LTx, this study adopted a qualitative research methodology which has been identified as an important next step for patient-centred research in transplantation.(28) Whilst a recent study aimed to determine young peoples' perspectives about the transition process (17) its quantitative methodology did not enable patients' perspectives to be explored to the same extent as in the current study. Using qualitative methodology allowed for an in-depth and unique insight into the direct experience of transition for young people with a LTX, with the methodology providing young people with the freedom to openly share 
their experiences without the confines of a questionnaire or survey structure. This in turn allowed for the revelation of potentially new insights which were particularly pertinent to the young people. Participants revealed compelling narratives which depicted both elements of successful transition experiences and components of transition that did not work for them. We included young people who had not yet transferred as well as those who had transferred and the many similarities between the two groups in terms of what they thought would happen (pre) and what did happen (post) in terms of relationships and interactions with professionals was noteworthy. Whilst the issues and experiences relate specifically to paediatric LTx recipients, the findings may be applicable to other transplant populations or those with other long-term conditions. Although transition services vary in their approach, they share a common goal - namely successful transition experiences for young people transferring from paediatric to adult services.

Feelings of anxiety and loss over the termination of relationships once transferred to adult care reflect those reported in the literature, where young people reported feeling "abandoned" and, for those with strong relationships, this loss was particularly difficult.(23, $29,30)$ The importance of relationships with paediatric clinicians identified in the current study corroborates previous findings $(10,11,31)$ and highlights how these relationships are an integral part of the LTx journey. Termination of these often lifelong relationships can be traumatic for young people and little attention is paid to appropriately managing the end of these relationships. A failure to promote closure of paediatric relationships prior to transfer results in a failure to equip young people to move on and form new and positive relationships with future adult care providers. $(30,32)$ Consideration of the anthropological concept of liminality is useful in this regard ie young people transferring to adult care are on the 
threshold of a new social position and rituals such as orientation visits and farewells are important in that they bring meaning to such change. (32) In this latter study the concept was explored in young people with cystic fibrosis transferring to adult services, where the authors identified that the absence of certain 'rites of passage' such as a recognised send-off from paediatrics might hinder a young person's progression towards becoming an adult patient. (32) Similarly, closure of paediatric relationships may be another rite of passage that would help to facilitate the move from paediatric to adult health care.

The theme of feeling unknown in adult care supports previous findings regarding the value of positive relationships between young people and clinicians. Young people in the current study described the importance of being known as a person rather than purely in terms of their liver transplant and treatment. Earning trust has been highlighted as essential when forming relationships with young people in a healthcare setting, with one particular study reporting duration of patient-physician relationships as a predictor of trust and that young people feel at least four to five visits are required in order for trust to be built.(33) Clinician attitude and communication are two key aspects of youth friendly healthcare identified in a recent systematic review.(34) Further research into key provider characteristics highlights the importance of clinician trustworthiness, earned through honesty and openness, mutual respect and having an approachable persona which is attuned to the needs of young people. $(33,35)$ Furthermore, the patient-centred nature of the adult provider has been reported to be a determinant of a positive transfer experience (36) and such provider characteristics to be a significant determinant of adolescent satisfaction with transitional care. $(37,38)$ Young people have previously identified that provider characteristics are more 
important than process issues or the physical environment in determining their satisfaction with a transitional care programme. (37)

In keeping with findings from other transition studies, a lack of continuity of care was highlighted by patients and viewed as a key factor to the success of transition. $(39,40)$ Of particular interest to the findings of this study is the work by Allen and colleagues (40) who found that an on-going therapeutic relationship between patients and healthcare professionals (relational continuity) and uninterrupted relationships with healthcare professionals (longitudinal continuity) were essential for smooth transitions, both of which were highlighted by young people in the current study. Seeing different care providers at each clinic visit (adult model) emphasises the absence of a substantial relationship with one clinician (paediatric model) and may obstruct the formation of future working relationships. With the social, psychological and biological changes that accompany adolescence, (41) a known increase in risk-taking behaviours in this age group $(42,43)$ and psychosocial issues for young people with special healthcare needs $(44,45)$ it is vital that trusting relationships are developed with adult clinicians to facilitate appropriate developmental care. The realities of adult service provision mean that seeing multiple clinicians is potentially unavoidable due to larger multi-disciplinary teams and patient numbers and this needs to be addressed by providing young people with the strategies to support rapport building with new clinicians.

\section{Limitations and implications for future study}

As data were collected when young people attended routine clinic appointments, the experiences of those who were lost to follow-up or did not attend clinic were not represented. It would have been useful to have gained the perspectives of such young people 
who do not engage with health services as this would have provided further insight into the barriers to successful transition. Such insights have been gained in patients who regularly did not attend a young adult's diabetes clinic revealing barriers to attendance including: inflexible hours, dislike of bureaucratic procedures and the anticipation of negative reactions from health professional.(46) Finally, although the aim of the study had been to look at the process of transition from the perspective of young people prior to or after transfer to adult services, in practice young people focused on the event of transfer itself. They found it difficult to describe any preparation they had had in terms of knowledge and skills and, despite the fact that all participants were seen in centres with existing transition programmes, their awareness of the process of transition appeared to be minimal. This suggests that transition is a professional concept and that there may be a need for both clinicians and researchers to reframe the process in the context of growing up.

The findings of this study support the development of interventions to support young people in transition, particularly in preparing them to manage the end of their relationships in paediatric services and in building capacity to form new relationships in adult care, thus helping them cope with the perception of a lack of continuity of care with clinicians. Enhanced follow-up in the period immediately following transfer to adult care has shown potential benefit in helping to establish relationships. $(8,47)$ Likewise consensus of management guidelines between paediatric and adult care providers is important to avoid inconsistencies which can in turn impact on how the young person trusts their new adult team. Further consideration of this strategy of transition management is required by paediatric and adult teams. Meeting and being supported by other patients during the 
period of transition and transfer was also identified by participants in our study as valuable, confirming other findings of the benefit of peer support during transition.(48)

In line with recommendations from previous studies in this area, there is a need to develop interventions to engage young people in self-management behaviours $(12,49,50)$ to improve confidence and communication skills with clinicians and better equip young people to cope once in adult care. There is clearly more that needs to be done in terms of patient awareness of and/or engagement with existing transition programmes and it is evident that the existence of a transition programme or attendance at a transition clinic are not sufficient young people (and their parents) need to be encouraged and empowered to engage meaningfully in the transition process. Furthermore, health professionals should ensure transitional care is embedded in developmentally appropriate adolescent health care rather than considered in isolation, which in turn will make it more relevant and meaningful to the lived experience of the young person in question.(51)

Finally, helping paediatric clinicians to facilitate closure of relationships with patients prior to transfer and conversely, adult clinicians to foster development of new relationships with the same patients will be key for success. Providing both paediatric and adult clinicians with resources and training in adolescent health and the acquisition of skills to communicate and engage with young people whilst being mindful of their holistic needs (52) will be an important next step in ensuring such relationships are built and that outcomes after transition are optimised. 
Acknowledgements and funding

The authors thank Sister Monica Smith, Philippa Lewis, Carla Lloyd and Dr Patrick McKiernan from Birmingham Children's Hospital, UK; Professor David Adams, Dr James Ferguson and Bridget Gunson from the Queen Elizabeth Hospital, Birmingham, UK; Dr Patricia McClean, Sister Lynne Henderson and Peter Sewell from the Leeds General Infirmary, UK; and Sister Jacqueline Jennings from St James' Hospital, Leeds, UK for their help in identifying and recruiting the patients. We also thank the patients who took part for their valuable contribution to the study and the Children's Liver Disease Foundation for their input as the representative for Patient and Public Involvement.

This study was funded by a research grant from BSPGHAN/CORE.

\section{Author contribution}

Jessica Wright: collection, analysis and interpretation of data; drafting of manuscript, approval of final manuscript

Laura Ellwell: analysis and interpretation of data; critical revision of manuscript; approval of final manuscript

Janet McDonagh: study design and concept; critical revision of manuscript; approval of final manuscript

Deirdre Kelly: study design and concept; critical revision of manuscript; approval of final manuscript Jo Wray: study design and concept; critical revision of manuscript; approval of final manuscript 


\section{References}

1. Amaria K, Stinson J, Cullen-Dean G, Sappleton K, Kaufman M. Tools for addressing systems issues in transition. Healthc $Q$ 2011: 14 Spec No 3: 72-76.

2. BLUM RW, GARELL D, HODGMAN CH, et al. Transition from child-centered to adult health-care systems for adolescents with chronic conditions. A position paper of the Society for Adolescent Medicine. J Adolesc Health 1993: 14: 570-576.

3. American Academy of Pediatrics, American Academy of Family Physicians, American College of PhysicIANS, AMERICAN SOCIETY OF INTERNAL MEDICINE. A consensus statement on health care transitions for young adults with special health care needs. Pediatrics 2002: 110: 1304-1306.

4. CANADIAN PAEDIATRIC SOCIETY. Transition to adult care for youth with special health care needs. Paediatr Child Health 2007: 12: 785-793.

5. DH. Transition: getting it right for young people. Improving the transition of young people with long term conditions from children's to adult health services. London: Department of Health; 2006.

6. McDonagh JE, SOUthWOOd TR, SHAW KL, BRITISH SOCIETY OF PAEDIATRIC AND AdOLESCENT RHEUMATOLOGY. The impact of a coordinated transitional care programme on adolescents with juvenile idiopathic arthritis. Rheumatology (Oxford) 2007: 46: 161-168.

7. MCDONAGH JE, VINER RM. Lost in transition? Between paediatric and adult services. BMJ 2006: 332: $435-436$.

8. CROWLEY R, WOLFE I, LOCK K, MCKEE M. Improving the transition between paediatric and adult healthcare: a systematic review. Arch Dis Child 2011: 96: 548-553.

9. Kennedy A, SLOMAn F, Douglass JA, SAWYer SM. Young people with chronic illness: the approach to transition. Intern Med J 2007: 37: 555-560.

10. LUGASI T, ACHILLE M, STEVENSON M. Patients' perspective on factors that facilitate transition from child-centered to adult-centered health care: a theory integrated metasummary of quantitative and qualitative studies. J Adolesc Health 2011: 48: 429-440.

11. REISS JG, GIBSON RW, WALKER LR. Health care transition: youth, family, and provider perspectives. Pediatrics 2005: 115: 112-120.

12. FREDERICKS EM, DORE-STITES D, WELL A, et al. Assessment of transition readiness skills and adherence in pediatric liver transplant recipients. Pediatr Transplant 2010: 14: 944-953.

13. FLUME PA, ANDERSON DL, HARDY KK, GRAY S. Transition programs in cystic fibrosis centers: perceptions of pediatric and adult program directors. Pediatr Pulmonol 2001: 31: 443-450.

14. RobertSON LP, MCDONAGH JE, SOUthWOOd TR, SHAW KL, BRITISH SOCIETY OF PAEDIATRIC AND AdolesCENT RHEUMATOLOgY. Growing up and moving on. A multicentre UK audit of the transfer of adolescents with juvenile idiopathic arthritis from paediatric to adult centred care. Ann Rheum Dis 2006: 65: 74-80.

15. WATSON AR. Problems and pitfalls of transition from paediatric to adult renal care. Pediatr Nephrol 2005: 20: 113-117.

16. HONG JC, YERSIZ H, FARMER DG, et al. Longterm outcomes for whole and segmental liver grafts in adult and pediatric liver transplant recipients: a 10-year comparative analysis of 2,988 cases. J Am Coll Surg 2009: 208: 682-689; discusion 689-691.

17. FREDERICKS EM, DORE-STITES D, LOPEZ MJ, et al. Transition of pediatric liver transplant recipients to adult care: patient and parent perspectives. Pediatr Transplant 2011: 15: 414-424. 
18. Annunziato RA, EMre S, Shneider B, BARTon C, DugAn CA, Shemesh E. Adherence and medical outcomes in pediatric liver transplant recipients who transition to adult services. Pediatr Transplant 2007: 11: 608-614.

19. DobBels F, VAN DAMme-Lombaert R, VANHAECKE J, De GeEST S. Growing pains: non-adherence with the immunosuppressive regimen in adolescent transplant recipients. Pediatr Transplant 2005: 9: 381-390.

20. SHEMESH E, SHNEIDER BL, SAVITZKY JK, et al. Medication adherence in pediatric and adolescent liver transplant recipients. Pediatrics 2004: 113: 825-832.

21. BRADLEY EH, CURRY LA, DEVERS KJ. Qualitative data analysis for health services research: developing taxonomy, themes, and theory. Health Serv Res 2007: 42: 1758-1772.

22. CAVET J, SLOPER P. The participation of children and young people in decisions about UK service development. Child Care Health Dev 2004: 30: 613-621.

23. LOCHRIDGE J, WOLFF J, OLIVA M, O'SULLIVAN-OliveIRA J. Perceptions of solid organ transplant recipients regarding self-care management and transitioning. Pediatr Nurs 2013: 39: 81-89.

24. KVALE S, BRINKMANN S. InterViews: Learning the craft of qualitative research interviewing. Thousand Oaks, CA: Sage, 2008.

25. SMITH JA, FLOWER P, LARKIN M. Interpretative Phenomenological Analysis: Theory, Method and Research. London: Sage, 2009.

26. HOWLAND S, FISHER K. Looking through the patient lens - Improving best practice for young people with juvenile idiopathic arthritis transitioning into adult care. Springerplus 2015: 4: 111.

27. SMITH JA, OSBORN M. Interpretative phenomenological analysis. In: SMITH JA, ed. Qualitative psychology: a practical guide to research methods. London: Taylor \& Francis, 2003. pp. 53-80.

28. TONG A, ChAPMAN JR, ISRANI A, GoRdon EJ, CRAIG JC. Qualitative research in organ transplantation: recent contributions to clinical care and policy. Am J Transplant 2013: 13: 1390-1399.

29. MILES K, EDWARDS S, CLAPSON M. Transition from paediatric to adult services: experiences of HIV-positive adolescents. AIDS Care 2004: 16: 305-314.

30. REISS J, GIBSON R. Health care transition: destinations unknown. Pediatrics 2002: 110: 13071314.

31. HARRIS MA, FREEMAN KA, DUKE DC. Transitioning from pediatric to adult health care: dropping off the face of the earth. American Journal of Lifestyle Medicine 2011: 5: 85-91.

32. TIERNEY S, DEATON C, JONES A, OXLEY H, BIESTY J, KIRK S. Liminality and transfer to adult services: a qualitative investigation involving young people with cystic fibrosis. Int J Nurs Stud 2013: 50: 738-746.

33. KLOSTERMANN BK, SLAP GB, NEBRIG DM, TIVORSAK TL, BRITTO MT. Earning trust and losing it: adolescents' views on trusting physicians. J Fam Pract 2005: 54: 679-687.

34. AMBRESIN AE, BENNETT K, PATTON GC, SANCI LA, SAWYER SM. Assessment of youth-friendly health care: a systematic review of indicators drawn from young people's perspectives. J Adolesc Health 2013: 52: 670-681.

35. Van StaA A, van der Stege HA, Jedeloo S, Moll ha, Hilberink SR. Readiness to transfer to adult care of adolescents with chronic conditions: exploration of associated factors. J Adolesc Health 2011: 48: 295-302.

36. VAN StAA A, SATTOE JN. Young adults' experiences and satisfaction with the transfer of care. J Adolesc Health 2014: 55: 796-803.

37. SHAW KL, SOUTHWOOd TR, MCDONAGH JE, BRITISH SOCIETY OF PAEDIATRIC AND AdOLESCENT RHEUMATOLOGY. Young people's satisfaction of transitional care in adolescent rheumatology in the UK. Child Care Health Dev 2007: 33: 368-379.

38. SHAW KL, WATANABE A, RANKIN E, MCDONAGH JE. Walking the talk. Implementation of transitional care guidance in a UK paediatric and a neighbouring adult facility. Child Care Health Dev 2014: 40: 663670.

39. Shaw KL, Southwood TR, McDonagh JE, BRitish Paediatric Rheumatology G. Transitional care for adolescents with juvenile idiopathic arthritis: a Delphi study. Rheumatology (Oxford) 2004: 43: 1000-1006.

40. Allen D, COHEN D, HOOD K, et al. Continuity of care in the transition from child to adult diabetes services: a realistic evaluation study. J Health Serv Res Policy 2012: 17: 140-148. 
41. Choudhury S, BLAKEMORE SJ, Charman T. Social cognitive development during adolescence. Soc Cogn Affect Neurosci 2006: 1: 165-174.

42. SURIS JC, MICHAUD PA, AKRE C, SAWYER SM. Health risk behaviors in adolescents with chronic conditions. Pediatrics 2008: 122: e1113-1118.

43. STEINBERG L. Risk taking in adolescence: what changes, and why? Annals of the New York Academy of Sciences 2004: 1021: 51-58.

44. ABRAMS AN, HAZEN EP, PENSON RT. Psychosocial issues in adolescents with cancer. Cancer Treat Rev 2007: 33: 622-630.

45. GeIST R, GRDISA V, OTLEY A. Psychosocial issues in the child with chronic conditions. Best Pract Res Clin Gastroenterol 2003: 17: 141-152.

46. SNOW R, FULOP N. Understanding issues associated with attending a young adult diabetes clinic: a case study. Diabet Med 2012: 29: 257-259.

47. Dugueperoux I, TAMAlet A, Sermet-Gaudelus I, et al. Clinical changes of patients with cystic fibrosis during transition from pediatric to adult care. J Adolesc Health 2008: 43: 459-465.

48. PATTERSON DL, LANIER C. Adolescent health transitions: focus group study of teens and young adults with special health care needs. Family \& Community Health 1999: 22: 43-58.

49. ANNUNZIATO RA, PARKAR S, DUGAN CA, et al. Brief report: Deficits in health care management skills among adolescent and young adult liver transplant recipients transitioning to adult care settings. J Pediatr Psychol 2011: 36: 155-159.

50. LaRosa C, GLAH C, BALUARTE HJ, MeYers KE. Solid-organ transplantation in childhood: transitioning to adult health care. Pediatrics 2011: 127: 742-753.

51. SCAL P. Improving Health Care Transition Services: Just Grow Up, Will You Please. JAMA Pediatr 2016: 170: 197-199.

52. VINER RM, BARKER M. Young people's health: the need for action. BMJ 2005: 330: 901-903. 
Table 1. Participant demographics

\begin{tabular}{ll}
\hline & Participants $\mathbf{( n = 1 7 ) ~ ( \% )}$ \\
\hline Gender & $7(41)$ \\
Male & $10(59)$ \\
Female & \\
\hline Age (years) & 20.0 \\
Mean & $15.2-25.1$ \\
Range & \\
\hline Indications for transplant & $3(18)$ \\
Acute liver disease & $14(82)$ \\
Chronic liver disease & \\
\hline Time post-LTx (years) & 10.3 \\
Mean & $1.2-20.3$ \\
Range & \\
\hline Living arrangements: & $12(71)$ \\
Living with parents & $5(29)$ \\
Living independently & \\
\hline Education/employment: & $9(53)$ \\
School/college/university & $2(12)$ \\
Employed & $6(35)$ \\
Unemployed & \\
\hline Transfer status & $8(47)$ \\
Pre-transfer & $9(53)$ \\
Post- transfer & \\
\hline Time post transfer (years) & 2.8 \\
Mean & $0-5.2$ \\
Range & \\
\hline &
\end{tabular}

